\title{
Sniff nasal inspiratory pressure as a marker of respiratory function in motor neuron disease
}

\author{
M.B. Chaudri*, C. Liu**, L. Watson*, D. Jefferson**, W.J. Kinnear*
}

Sniff nasal inspiratory pressure as a marker of respiratory function in motor neuron disease. M.B. Chaudri, C. Liu, L. Watson, D. Jefferson, W.J. Kinnear. (C) ERS Journals Ltd 2000. ABSTRACT: Vital capacity (VC) and maximum mouth pressures are often used to monitor respiratory function in motor neuron disease (MND), but require the use of a mouthpiece. Sniff nasal inspiratory pressure (SNIP) is a simple and reliable means of measuring inspiratory muscle strength; it does not involve the use of a mouthpiece and might therefore be better than VC or mouth pressures for assessing patients with bulbar disease.

SNIP, maximum inspiratory (MIP) and expiratory mouth pressure (MEP), VC and arterial carbon dioxide tension $\left(\mathrm{Pa}_{2}, \mathrm{CO}_{2}\right)$ were measured in 59 consecutive patients attending a specialist MND clinic. Thirty-one had bulbar involvement on clinical grounds.

Both SNIP and VC were inversely related to $\mathrm{Pa}_{2} \mathrm{CO}_{2}$ in nonbulbar patients only. Neither MIP nor MEP were related to $\mathrm{Pa}_{1}, \mathrm{CO}_{2}$. The 10 patients with an elevated $\mathrm{Pa}_{2}, \mathrm{CO}_{2}$ $(>6 \mathrm{kPa}$ ) had significantly lower SNIP and VC than normocapnic patients.

Sniff nasal inspiratory pressure can be used to monitor respiratory function in motor neuron disease. It is quick and easy for patients to perform, but otherwise appears to offer little advantage over vital capacity measurement. Patients with bulbar disease are often poor at performing sniff nasal inspiratory pressure manoeuvres, possibly because of upper airway collapse or inability to close the mouth completely during the manoeuvre.

Eur Respir J 2000; 15: 539-542.

Depts of *Respiratory Medicine and ingham, UK.

Correspondence: W.J. Kinnear

University Hospital

Derby Road

Nottingham NG7 2UH

UK

Fax: 441159194403

Keywords: Bulbar function

hypercapnia

motor neuron disease

respiratory muscle weakness

sniff nasal inspiratory pressure

vital capacity

Received: June 151999

Accepted after revision November 251999

This study was supported by the Motor Neurone Disease Care and Research Centre, Queen's Medical Centre, Nottingham, UK.

Motor neuron disease (MND) is a progressive and devastating neurodegenerative condition characterized by wasting and weakness of affected muscle groups. The usual cause of death is respiratory failure due to increasing respiratory muscle weakness [1]. Respiratory function can be assessed via pulmonary function tests, such as measurement of vital capacity (VC) or forced VC. These decline with time and are a good method of gauging disease progression $[2,3]$. Maximal mouth inspiratory (MIP) and expiratory pressure (MEP) have traditionally been used as a measure of inspiratory and expiratory muscle strength. These involve maximal efforts against an occlusion. However the manoeuvres are dependent on patient coordination and cooperation, and there is a considerable learning effect [4]. All of these tests are more likely to be unreliable in patients with significant bulbar disease who often have upper airways dysfunction [5], and may experience difficulty inserting or gripping the mouthpiece.

Measurement of sniff nasal inspiratory pressure (SNIP) is a simple, reliable and reproducible test for assessing inspiratory muscle strength [6-8]. There is a learning effect, but it does not require a mouthpiece and involves a more natural manoeuvre than do measurements of $\mathrm{VC}$, MIP and MEP. The relationship between SNIP and VC was studied and the value of SNIP measurement in patients with MND compared with measurements of VC, MIP or MEP in predicting critical respiratory muscle weakness as indicated by an arterial carbon dioxide tension $\left(P \mathrm{a}, \mathrm{CO}_{2}\right)>6 \mathrm{kPa}$.

\section{Methods}

Fifty-nine consecutive patients attending a weekly specialist MND clinic between May 1998 and January 1999 were studied. Verbal consent was obtained. All had previously seen a neurologist (D. Jefferson) and were diagnosed as having MND according to the EI Escorial criteria [9]. The disease was categorized as bulbar or nonbulbar on clinical grounds. Bulbar involvement was defined by a history of dysphagia, dysarthria or drooling, with signs of increased jaw jerk and/or wasting, fasciculation or spasticity of the tongue.

Blood gas levels were measured in arterialized capillary samples using a blood gas analyser (Ciba-Corning 840 Ciba-Corning Diagnostics, Halstead, UK). SNIP was measured using previously described methods [7]. Measurements were made at functional residual capacity with the patients seated comfortably, using a hand-held meter (Pmax Monitor, P.K. Morgan, Rainham, UK). This was attached to the base of a 10-mL syringe (Beckton Dickinson, Madrid, Spain), at the end of which an ADAM Nasal Pillow (Puritan Bennett, Lexana, Kansas, USA) was attached (fig. 1). The latter was inserted into the nostril. The volume of air in the system was $15.8 \mathrm{~mL}$ and the $10-90 \%$ response time for a $100-\mathrm{cmH}_{2} \mathrm{O}$ square wave change in pressure was $0.007 \mathrm{~s}$ [10]. The patients were instructed to take a series of short sharp sniffs with the mouth closed, each $20 \mathrm{~s}$ apart. The highest of five results was recorded. Readings were taken from both nostrils.
\end{abstract}




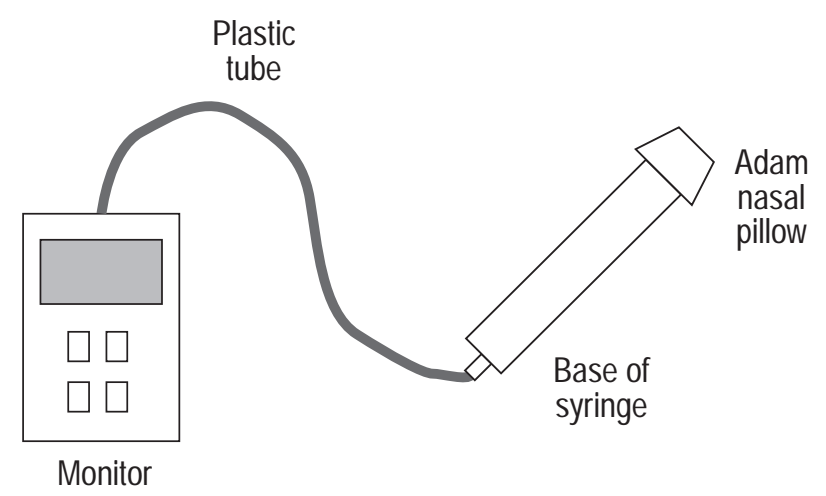

Fig. 1. - Diagram of apparatus used to record sniff nasal inspiratory pressure.

SNIPs were then expressed as a percentage of the predicted value using the equation described by ULDRY and FitTiNG [11].

VC was recorded using a wedge bellows spirometer(Vitalograph, Maids Moreton, UK) with the patient seated. A nose clip was applied during the expiratory phase of the manoeuvre. The highest of three results was recorded. A tight fitting face mask (Respironics, Medic-Aid, Bognor Regis, UK) was used in patients who were unable to insert the mouthpiece. As with SNIP, the results were expressed as a percentage of the predicted value [12]. Maximal mouth pressures were measured with the patient seated using a flanged mouthpiece, which was attached via a plastic tube to the same hand-held meter. The plastic tube had a 22gauge leak to prevent glottic closure. The nose was occluded with a nose clip during the procedure. MIPs were obtained by asking the patient to perform an inspiratory effort from residual volume. For measurement of MEP, the patient performed an expiratory effort from total lung capacity with the hands pressed against the cheeks. The highest of three results, maintained for $\geq 1 \mathrm{~s}$, was recorded for both MIP and MEP. As with VC, a face mask was used in patients who had difficulty inserting the mouthpiece. The results were expressed as a percentage of the predicted value [13].

Statistical analysis was performed using Arcus Quickstat for Windows (Addison Wesley Longman, Cambridge, UK). The Mann-Whitney U-test was used to compare mean data in different subgroups. Spearman's rank correlation coefficient $(\mathrm{r})$ was used to examine the relationships between SNIP, MIP, MEP, VC and $\mathrm{Pa}_{2} \mathrm{CO}_{2}$. Linear regression and multivariate analysis allowed the relationships between individual measurements and $\mathrm{Pa}_{\mathrm{a}} \mathrm{CO}_{2}$ to be defined. A p-value $<0.05$ was taken as significant.

Table 1. - Anthropometric data in patients with bulbar and nonbulbar disease

\begin{tabular}{lccc}
\hline & Bulbar & Nonbulbar & p-value \\
\hline Subjects n & 31 & 28 & - \\
Age yrs & $61.5 \pm 15.2$ & $59.3 \pm 10.5$ & NS \\
Sex M/F & $18 / 13$ & $26 / 2$ & 0.01 \\
BMI kg.m ${ }^{-2}$ & $23.6 \pm 3.1$ & $24.7 \pm 4.6$ & NS \\
Disease duration months & $26.3 \pm 23.7$ & $23.7 \pm 11.4$ & NS \\
\hline
\end{tabular}

Data are presented as mean \pm sd. M: male; F: female; BMI: body mass index.
Table 2. - Results in patients with bulbar and nonbulbar disease

\begin{tabular}{lclc}
\hline & Bulbar & Nonbulbar & p-value \\
\hline VC \% pred & $52.3 \pm 21$ & $75.4 \pm 21.9$ & $<0.001$ \\
SNIP \% pred & $30 \pm 14.3$ & $46.2 \pm 24.1$ & 0.01 \\
MIP \% pred & $15.7 \pm 10.4$ & $34.1 \pm 22.2$ & $<0.001$ \\
MEP \% pred & $19.4 \pm 10.3$ & $56.6 \pm 37.8$ & $<0.001$ \\
$\mathrm{~Pa}_{\mathrm{a}} \mathrm{CO}_{2} \mathrm{kPa}$ & $5.30 \pm 1.1$ & $5.17 \pm 1.2$ & NS \\
\hline
\end{tabular}

Data are presented as mean \pm SD. VC: vital capacity; SNIP: sniff nasal inspiratory pressure; MIP: maximal inspiratory mouth pressure; MEP: maximal expiratory mouth pressure; $P \mathrm{a}_{2} \mathrm{CO}_{2}$ : arterial carbon dioxide tension.

\section{Results}

Of the 59 patients, 31 had bulbar and 28 nonbulbar disease. Their anthropometric data are shown in table 1 . There were no significant differences between the two groups in respect of age, body mass index (BMI) and disease duration but there was a male preponderance in the nonbulbar group.

Table 2 shows the results of vital capacity, respiratory muscle strength and $\mathrm{Pa}_{\mathrm{a}} \mathrm{CO}_{2}$ measurement. All values other than $\mathrm{Pa}, \mathrm{CO}_{2}$ were significantly greater in the nonbulbar group.

Ten patients (five bulbar, five nonbulbar) had a $\mathrm{Pa}_{\mathrm{a}}, \mathrm{CO}_{2}$ of $\geq 6 \mathrm{kPa}$ They had significantly lower SNIPs and VCs but similar MIPs and MEPs to normocapnic patients (table 3).

Figure $2 \mathrm{a}$ and $\mathrm{b}$ shows the relations between $\mathrm{VC}$ and $P \mathrm{a}, \mathrm{CO}_{2}$ in nonbulbar and bulbar patients. The regression equation for nonbulbar patients was $P_{\mathrm{a}}, \mathrm{CO}_{2}=16.34-2.61$ $\operatorname{lnVC}$, but there was no statistically significant regression line in the bulbar group. Figure $3 \mathrm{a}$ and $\mathrm{b}$ shows the relations between SNIP and $\mathrm{Pa}_{\mathrm{a}} \mathrm{CO}_{2}$. As for VC, this was only significant in patients with nonbulbar disease, the regression equation being $\mathrm{Pa}_{\mathrm{a}} \mathrm{CO}_{2}=10.48-1.44 \ln$ SNIP.

Neither MIP nor MEP were significantly related to $\mathrm{Pa}_{\mathrm{a}} \mathrm{CO}_{2}$. Receiver operating characteristic curves were constructed in order to define the optimum cut-off points for predicting hypercapnia. AVC of $<49 \%$ and an SNIP of $<26 \%$ were predictive. The sensitivity $(90 \%)$ and specificity (73.5\%) of these values were the same for both VC and SNIP.

Figure $4 \mathrm{a}$ and $\mathrm{b}$ shows the relations between SNIP and $\mathrm{VC}$ in patients with nonbulbar and bulbar disease. The regression equation in nonbulbar patients was $\mathrm{VC}=28.7$ lnSNIP-28.81. In bulbar patients, it was VC=0.83SNIP+ 26.99 .

Table 3. - Measurements in normocapnic and hypercapnic patients

\begin{tabular}{lccc}
\hline & $P \mathrm{a}, \mathrm{CO}_{2}<6 \mathrm{kPa}$ & $P \mathrm{a}, \mathrm{CO}_{2} \geq 6 \mathrm{kPa}$ & $\mathrm{p}$-value \\
\hline Subjects n & 49 & 10 & - \\
VC \% pred & $67.1 \pm 24.4$ & $46.7 \pm 14.6$ & $<0.05$ \\
SNIP \% pred & $40.8 \pm 21.3$ & $22 \pm 9.6$ & 0.01 \\
MIP \% pred & $25.3 \pm 20.3$ & $20.3 \pm 13.7$ & NS \\
MEP \% pred & $28.5 \pm 23.9$ & $26.9 \pm 17.7$ & NS \\
\hline
\end{tabular}

Data are presented as mean \pm SD. $P \mathrm{a}, \mathrm{CO}_{2}$ : arterial carbon dioxide tension; VC: vital capacity; SNIP: sniff nasal inspiratory pressure; MIP: maximal inspiratory mouth pressure; MEP: maximal expiratory mouth pressure. 

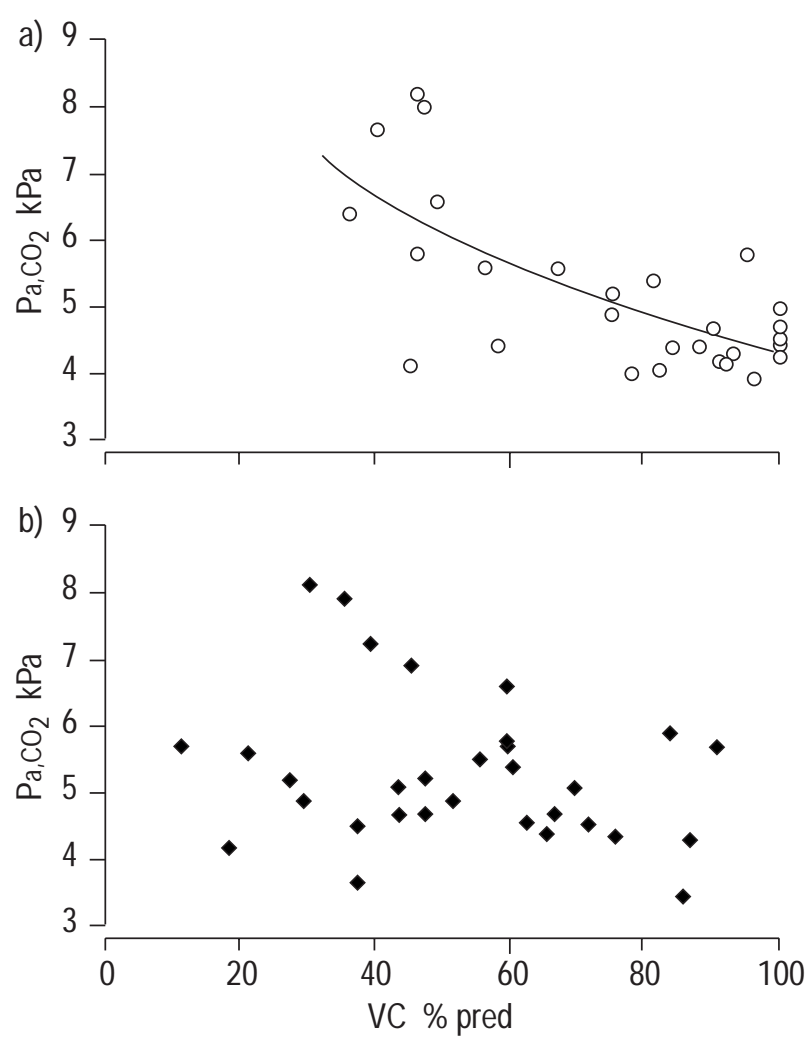

Fig. 2. - Relations between arterial carbon dioxide tension $\left(P \mathrm{a}, \mathrm{CO}_{2}\right)$ and vital capacity (VC) in patients with: a) nonbulbar disease (regression line: $\left.P \mathrm{a}, \mathrm{CO}_{2}=16.34-2.61 \ln \mathrm{VC} ; \mathrm{R}^{2}=0.49, \mathrm{r}=-0.44, \mathrm{p}<0.05\right)$; and $\mathrm{b}$ ) bulbar disease (NS).

\section{Discussion}

The sniff test has been used for many years during radiographic screening of diaphragmatic movement. Measurement of oesophageal and gastric pressures during sniffs was described by MiLLER et al. [14]. Recently SNIP has been introduced as a noninvasive index of inspiratory muscle strength, with a normal range formulated according to age and sex.

This study demonstrates that, in patients with normal bulbar function, SNIP is related to VC in a curvilinear fashion. The relation between $\mathrm{VC}$ and respiratory muscle strength was described by BRAUN et al. [15] in patients with other neuromuscular disease, and attributed to the sigmoid shape of the pressure volume curve of the respiratory system. A similar relation has also been observed in MND [16-18]. SNIP measurement could therefore be of value in detecting involvement of the respiratory muscles at an early stage, when VC is well preserved.

The relation between VC and SNIP appeared to be linear in the present patients with bulbar disease, and the correlation was less close. The authors' original hypothesis was that these patients would be better able to perform SNIP than VC manoeuvres, and that there would be a subgroup in whom SNIP was well preserved but VC was spuriously low. This was not the case, and bulbar patients were poor at performing SNIP, VC and maximum mouth pressure manoeuvres. The fact that similar numbers of patients were hypercapnic in the bulbar and nonbulbar groups argues against the possibility that the bulbar patients had
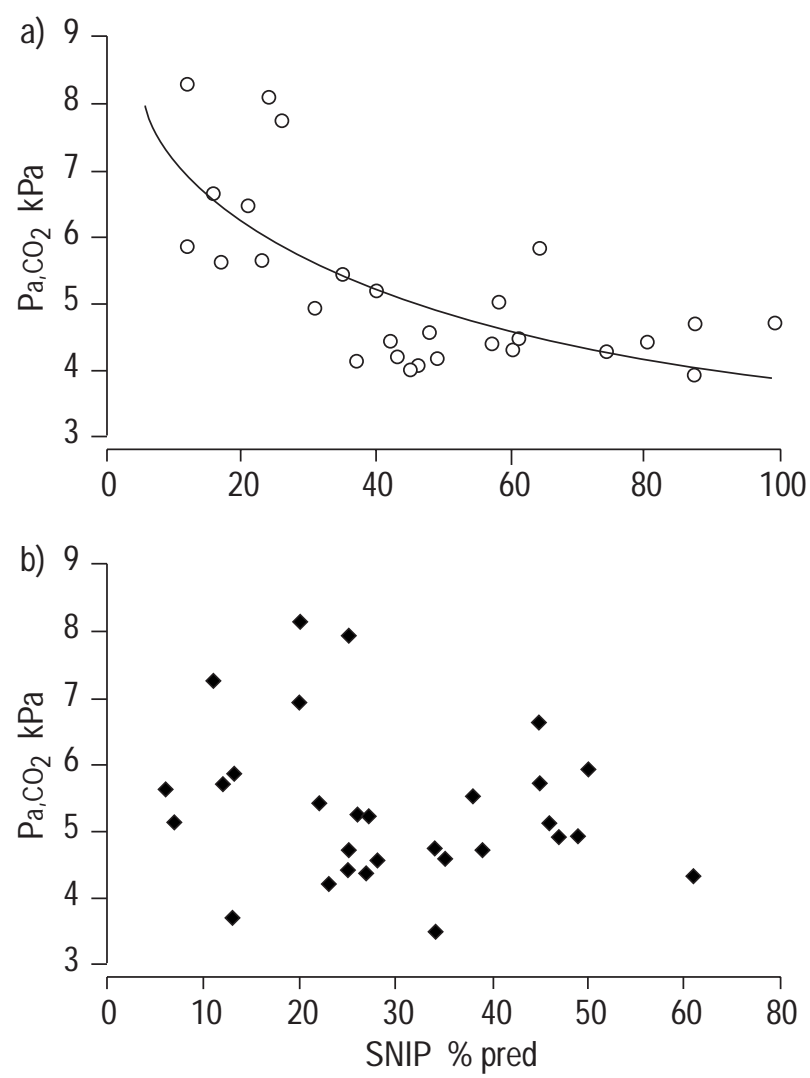

Fig. 3. - Relations between arterial carbon dioxide tension $\left(\mathrm{Pa}_{\mathrm{a}}, \mathrm{CO}_{2}\right)$ and sniff nasal inspiratory pressure (SNIP) in patients with: a) nonbulbar disease (regression line: $P \mathrm{a}, \mathrm{CO}_{2}=10.48-1.44 \ln \mathrm{SNIP} ; \mathrm{R}^{2}=0.49, \mathrm{r}=-0.6$, $\mathrm{p}<0.01$ ); and $\mathrm{b}$ ) bulbar disease.

more severe respiratory muscle involvement as the explanation for their low results. The authors feel that this reflects the problems that they experienced in performing the manoeuvres, mainly because of difficulty in sealing the mouth. Other factors possibly contributing to the low values in bulbar patients include upper airway collapse and disco-ordinated/dyspractic contraction of the various respiratory and upper airway muscles during the tests, both of which would mainly affect dynamic manoeuvres such as the sniff test. Bulbar dysfunction, as indicated by abnormalities in the flow/volume loop, has previously been noted to have either no effect on maximum mouth pressures [5], or to be associated with a reduction in the values obtained [19].

Despite these reservations, in the present patients, SNIP was better than MIP or MEP in identifying patients with hypercapnia. Polkey et al. [20] showed that hypercapnia is related to inspiratory rather than expiratory strength. Compared to MEP or indeed VC, to which both expiratory and inspiratory muscles contribute, SNIP and MIP might be expected to correlate more closely with $\mathrm{Pa}_{\mathrm{a}}, \mathrm{CO}_{2}$. The present failure to demonstrate a relationship between MIP and $P \mathrm{a}, \mathrm{CO}_{2}$ could be explained by the patients finding the SNIP manoeuvre easier to perform, or by differences in the pattern of muscle recruitment during these two different manoeuvres [21].

Sniff nasal inspiratory pressure monitoring is a simple and easy alternative to vital capacity which could be used to monitor respiratory muscle function in patients with 

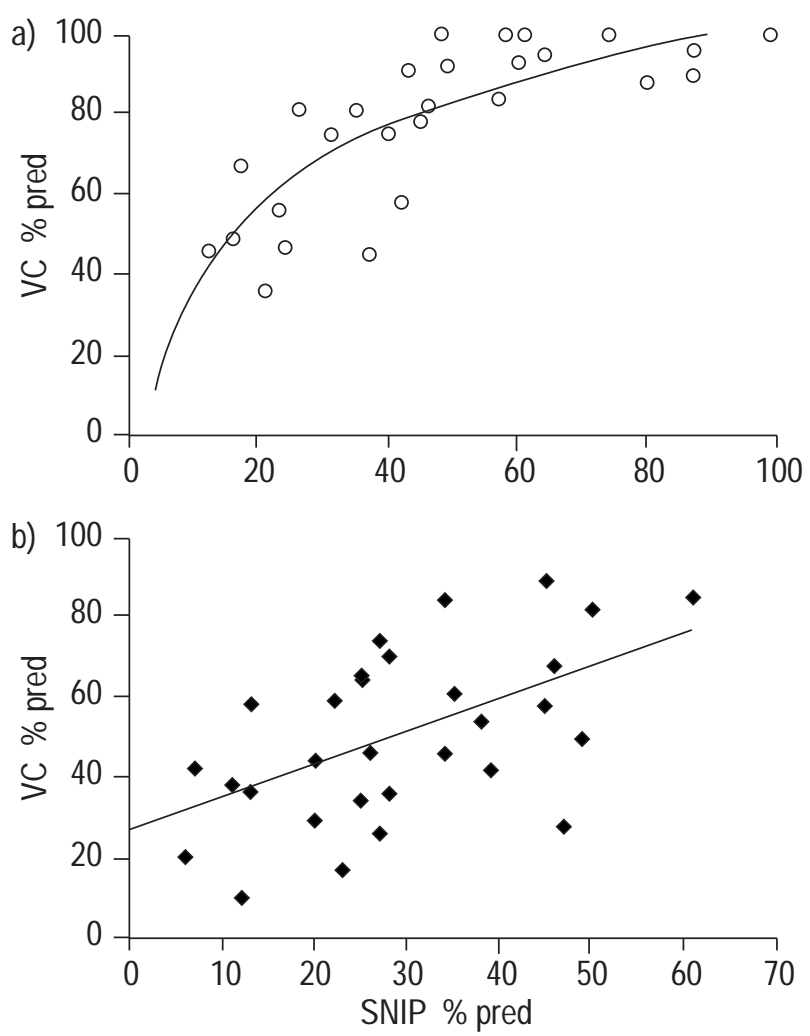

Fig. 4. - Relations between vital capacity (VC) and sniff nasal inspiratory pressure (SNIP) in patients with: a) nonbulbar disease (regression line: $\left.\mathrm{VC}=28.7 \ln S N I P-28.81 ; \mathrm{R}^{2}=0.68, \mathrm{r}=0.85, \mathrm{p}<0.001\right)$; and $\mathrm{b}$ ) bulbar disease (regression line: $\mathrm{VC}=0.83 \mathrm{SNIP}+26.99 ; \mathrm{R}^{2}=0.311, \mathrm{r}=0.52$, $\mathrm{p}<0.01)$.

motor neuron disease. Patients with a sniff nasal inspiratory pressure of $<30 \%$ of the predicted value are at risk of developing hypercapnia and should have their arterial blood gas levels measured. Vital capacity remains the best index of respiratory function in this disease; it is insensitive to early respiratory muscle involvement, but, in clinical practice, this is not a major disadvantage. Patients with motor neuron disease being assessed in respiratory clinics or the lung function laboratory should have both vital capacity and sniff nasal inspiratory pressure measured.

\section{References}

1. Caroscio JT, Mulvihill MN, Sterling R, Abrams B. Amyotrophic lateral sclerosis: its natural history. Neurol Clin 1987; 5: 1-8.

2. Schiffman PL, Belsh JM. Pulmonary function at diagnosis of amyotrophic lateral sclerosis: rate of deterioration. Chest 1993; 103: 508-513.

3. Fallat RJ, Jewitt B, Bass M, Kamm B, Norris FH Jr. Spirometry in amyotrophic lateral sclerosis. Arch Neurol 1979; 36: 74-80.

4. Laroche CM, Mier AK, Moxham J, Green M. The value of sniff oesophageal pressures in the assessment of global inspiratory muscle strength. Am Rev Respir Dis 1988; 138: 598-603.

5. Vincken W, Elleker G, Cosio MG. Detection of upper airway muscle involvement in neuromuscular disorders using the flow-volume loop. Chest 1986; 90: 52-57.

6. Koulouris N, Mulvey DA, Laroche CM, Sawicka EH, Green M, Moxham J. The measurement of inspiratory muscle strength by sniff esophageal, nasopharyngeal, and mouth pressures. Am Rev Respir Dis 1989; 139: 641-646.

7. Heritier F, Rahm F, Pasche P, Fitting JW. Sniff nasal inspiratory pressure. A noninvasive assessment of inspiratory muscle strength. Am J Respir Crit Care Med 1994; 150: $1678-1683$.

8. Maillard JO, Burdet L, van Melle G, Fitting JW. Reproducibility of twitch mouth pressures, sniff nasal inspiratory pressure, and maximal inspiratory pressure. Eur Respir J 1998; 11: 901-905.

9. World Federation of Neurology Research Group on Neuromuscular diseases. Subcommittee on motor neurone disease. El Escorial World Federation of Neurology criteria for the diagnosis of amyotrophic lateral sclerosis. J Neurol Sci 1994; 124 (Suppl.): 96-107.

10. Mead J, McIlroy MB, Selverstone NJ, Kriete BC. Measurement of intraesophageal pressure. J Appl Physiol 1955; 7: 491-495.

11. Uldry C, Fitting JW. Maximal values of sniff nasal inspiratory pressure in healthy subjects. Thorax 1995; 50: 371-375.

12. Quanjer PH. Standardised lung function testing - lung volumes and forced ventilatory flows. Eur Respir J 1993; 6 (Suppl. 16): 5-40.

13. Bruschi C, Cerveri I, Zoia MC, et al. Reference values of maximal respiratory mouth pressures: a population-based study. Am Rev Respir Dis 1992; 146: 790-793.

14. Miller JM, Moxham J, Green M. The maximal sniff in the assessment of diaphragm function in man. Clin Sci 1985; 69: 91-96.

15. Braun NMT, Arora NS, Rochester DF. Respiratory muscle and pulmonary function in polymyositis and other proximal myopathies. Thorax 1983; 38: 616-623.

16. Kreizer SM, Saunders NA, Tyler HR, Ingram RH Jnr. Respiratory muscle function in amyotrophic lateral sclerosis. Am Rev Respir Dis 1978; 117: 437-447.

17. Black LF, Hyatt RE. Maximal static respiratory pressures in generalized neuromuscular disease. Am Rev Respir Dis 1971; 103: 641-650.

18. Vitacca M, Clini E, Facchetti D, et al. Breathing pattern and respiratory mechanics in patients with amyotrophic lateral sclerosis. Eur Respir J 1997; 10: 1614-1621.

19. Garcia-Pachon E, Marti J, Mayos M, Casan P, Sanchis J. Clinical significance of upper airway dysfunction in motor neurone disease. Thorax 1994; 49: 896-900.

20. Polkey MI, Lyall RA, Green M, Leigh PN, Moxham J. Expiratory muscle function in amyotrophic lateral sclerosis. Am J Respir Crit Care Med 1998; 158: 734-741.

21. Nava S, Ambrosino N, Crotti P, Fracchia C, Rampulla C. Recruitment of some respiratory muscles during three maximal inspiratory manoeuvres. Thorax 1993; 48: 702-707. 